\title{
Modeling EBV infection and pathogenesis in new-generation humanized mice
}

\author{
Shigeyoshi Fujiwara ${ }^{1,2}$, Ken-Ichi Imadome ${ }^{1}$ and Masami Takei ${ }^{2}$ \\ The development of highly immunodeficient mouse strains has allowed the reconstitution of functional human immune system \\ components in mice. New-generation humanized mice generated in this manner have been extensively used for modeling viral \\ infections that are exclusively human tropic. Epstein-Barr virus (EBV)-infected humanized mice reproduce cardinal features of \\ EBV-associated B-cell lymphoproliferative disease and EBV-associated hemophagocytic lymphohistiocytosis (HLH). Erosive \\ arthritis morphologically resembling rheumatoid arthritis (RA) has also been recapitulated in these mice. Low-dose EBV infection \\ of humanized mice results in asymptomatic, persistent infection. Innate immune responses involving natural killer cells, \\ EBV-specific adaptive T-cell responses restricted by human major histocompatibility and EBV-specific antibody responses are \\ also elicited in humanized mice. EBV-associated T-/natural killer cell lymphoproliferative disease, by contrast, can be reproduced \\ in a distinct mouse xenograft model. In this review, recent findings on the recapitulation of human EBV infection and \\ pathogenesis in these mouse models, as well as their application to preclinical studies of experimental anti-EBV therapies, \\ are described.
}

Experimental \& Molecular Medicine (2015) 47, e135; doi:10.1038/emm.2014.88; published online 23 January 2015

\section{ANIMAL MODELS OF EPSTEIN-BARR VIRUS INFECTION} Humans are the only natural host of Epstein-Barr virus (EBV). The cotton-top tamarin (Saguinus oedipus), a new-world monkey, can be experimentally infected with EBV via parenteral routes and develops B-cell lymphomas. ${ }^{1}$ Cotton-top tamarins were therefore used in a preclinical study to demonstrate the efficacy of an experimental EBV subunit vaccine consisting of the major envelope glycoprotein gp $350 .^{2}$ However, these animals are an endangered species and are not readily available for experimental use. Other new-world monkeys, such as the common marmoset (Callithrix jacchus) and the owl monkey (Aotus trivirtatus), can also be infected experimentally with EBV, but they have not been characterized in detail as animal models., ${ }^{3,4}$ Recent experiments have shown that rabbits can be infected with EBV. Rabbits of the Japanese White and the New Zealand White strains were found to develop persistent EBV infection, with viral DNA detected in the peripheral blood lymphocytes and with the production of anti-EBV antibodies. ${ }^{5,6}$ Notably, rabbits could be infected orally, recapitulating the normal route of human EBV infection. ${ }^{6,7}$ However, EBV-infected rabbits do not appear to reproduce the distinct human diseases caused by the virus. ${ }^{5-7}$
EBV belongs to the genus lymphocryptovirus (LCV) of the $\gamma$-herpesvirus subfamily. EBV is thought to have evolved with its host species, and each non-human primate species carries its own characteristic LCV with genetic homology and biologic similarities with EBV. The rhesus LCV has been most extensively studied as a surrogate model of human EBV infection. ${ }^{8,9}$ The rhesus LCV genome encodes an identical repertoire of genes to those in EBV, with high degrees of homology in the lytic-cycle genes (49-98\% amino-acid identity) and moderate homology in the latent-cycle genes (28-60\%). ${ }^{9}$ Rhesus monkeys can be infected orally with rhesus LCV and occasionally present mononucleosis-like symptoms, including atypical lymphocytosis and splenomegaly. ${ }^{9}$ Similar to EBV, rhesus LCV induces opportunistic B-cell lymphomas in immunocompromised hosts. ${ }^{9}$ Immunization of rhesus monkeys with the rhesus LCV homolog of EBV gp350 was found to result in partial protection of the animals from infection. ${ }^{10}$ These findings indicate that rhesus LCV is an outstanding surrogate model, reproducing various aspects of human EBV infection. Murine gammaherpesvirus $68^{11}$ shares a number of properties with EBV, including the ability to induce a mononucleosis-like syndrome and to establish persistent

\footnotetext{
${ }^{1}$ Department of Infectious Diseases, National Research Institute for Child Health and Development, Tokyo, Japan and ${ }^{2}$ Division of Hematology and Rheumatology, Department of Medicine, Nihon University School of Medicine, Tokyo, Japan

Correspondence: Dr S Fujiwara, Department of Infectious Diseases, National Research Institute for Child Health and Development, 2-10-1 Okura, Setagaya-ku, Tokyo 157-8535, Japan.

E-mail: fujiwara-s@ncchd.go.jp
}

Received 11 September 2014; accepted 29 September 2014 
infection in memory B cells. ${ }^{12}$ However, some key features of human EBV infection, including B-cell transformation, are not reproduced by murine gammaherpesvirus 68 . Murine gammaherpesvirus 68 belongs to the genus rhadinovirus of the $\gamma$-herpesvirus subfamily, and its genetic homology with EBV is restricted to the lytic-cycle genes and does not extended to the latent-cycle genes. ${ }^{12}$ In this sense, murine gammaherpesvirus 68 may be a better model for Kaposi's sarcoma-associated herpesvirus infection than for EBV infection. Overall, these surrogate models of EBV infection described above are inadequate from the following standpoints: first, no reliable small animal models, required especially for preclinical studies of novel therapies and vaccines, are available. Second, the specific interactions that occur between EBV and human cells are not reproduced in these models.

A breakthrough in the generation of a small animal model of EBV infection was brought about by the development of the scid-hu PBL mouse, which is based on the C.B-17 scid mouse. ${ }^{13}$ C.B-17 scid mice lack both B and T cells because of a mutation in the gene coding for a subunit of DNA-dependent protein kinase, an essential enzyme for the molecular reconstitution of the $\mathrm{B}$ - and T-cell antigen receptor genes. ${ }^{14}$ Intraperitoneal injection of peripheral blood mononuclear cells (PBMCs) isolated from healthy EBV carriers into C.B-17 scid mice was found to result in the development of EBV-positive B-cell lymphoproliferative disease (LPD). Analyses of the histology, marker expression and EBV gene expression revealed that this LPD is similar to the representative type of EBV-associated LPD in immunocompromised hosts. A number of interesting observations regarding the biology of EBV-induced lymphoproliferation and experimental therapies for EBV-associated B-cell LPD were obtained from experiments with scid-hu PBL mice (reviewed by Johannessen and Crawford ${ }^{4}$ and Fujiwara et al. $\left.{ }^{15}\right)$.

\section{NEW-GENERATION HUMANIZED MICE}

Although scid-hu PBL mice have been a valuable tool for studying EBV-induced lymphoproliferation in a small animal model, they have certain limitations, including the transient nature of engraftment, low engraftment levels and frequent graft-versus-host disease caused by human $\mathrm{T}$ cells attacking mouse tissues. More importantly, they lacked human immune responses to EBV. These shortcomings were largely overcome when the new generation of humanized mice was produced based on novel immunodeficient mouse strains. Transplantation of human hematopoietic stem cells (HSCs) into mice of strains such as NOD/Shi-scid $I l 2 r g^{\text {null }}$ (NOG), ${ }^{16} \mathrm{BALB} / \mathrm{c}$ $\mathrm{Rag}^{-1-} \mathrm{Il}_{2 \mathrm{rg}^{-/-17}}$ and NOD/LtSz-scid Il2rg- ${ }^{-1-}(\mathrm{NSG})^{18}$ was found to result in the reconstitution of functional human immune system components, including B cells, T cells, natural killer (NK) cells, dendritic cells and macrophages. Mice with human immune system components prepared in this manner are called new-generation humanized mice and have been used extensively for studying the development and function of human immune system components in vivo. ${ }^{19}$ In addition, these mice have been used for modeling infections with various pathogens that are exclusively human tropic, including EBV, human immunodeficiency virus type 1, dengue virus and Salmonella typhi. ${ }^{20,21}$ Traggiai et al. ${ }^{17}$ were the first to show that humanized BALB/C Rag2 ${ }^{-/} I l 2 \mathrm{rg}^{-/-}$mice can be infected with EBV and suggested that these mice may be able to mount T-cell responses specific to the virus. ${ }^{17}$ Melkus et al. ${ }^{22}$ transplanted NOD/scid mice with human fetal thymic and liver grafts, as well as with $\mathrm{CD}^{+} 4^{+}$stem cells isolated from the same liver graft, to prepare BLT (bone marrow-liverthymus)-NOD mice. BLT-NOD mice were found to mount EBV-specific T-cell responses restricted by human major histocompatibility complex (MHC) ${ }^{22}$ Following these pioneering studies, several groups have used various strains of newgeneration humanized mice to recapitulate the key features of human EBV infection, including pathogenesis, latent infection and immune responses (Figure 1).

\section{EBV PATHOGENESIS IN HUMANIZED MICE}

\section{B-cell LPD}

In humanized mice, EBV induces a B-cell LPD remarkably similar to the EBV-associated LPD in immunocompromised patients. The majority of humanized NOG mice inoculated with $>10^{2} 50 \%$ transforming dose of EBV were shown to develop B-cell LPD. ${ }^{23}$ Macroscopically, all mice were found to develop splenomegaly, and a fraction of them had tumors in the spleen, liver, kidney and/or adrenal glands. Histologically, EBV-infected B lymphoblastoid cells expressing EBV-encoded small RNA, EBV nuclear antigen 2 (EBNA2) and latency membrane protein 1 (LMP1) were recognized in these tumors, showing latency III-type EBV gene expression. These EBVinfected cells expressed the B-cell markers CD19 and CD20, the B-cell activation marker CD23 and the germinal center marker Mum-1. Histology of this LPD was consistent with diffuse large B-cell lymphoma. B-cell LPD induced in the humanized NOG mice was thus remarkably similar to the representative diffuse large B-cell lymphoma type that occurs in posttransplant LPD and AIDS-associated lymphomas. ${ }^{23}$ Similar B-cell LPD has also been reported following EBV infection of humanized NSG mice and BLT NSG mice. ${ }^{24-27}$ In addition to this diffuse large B-cell lymphoma-type LPD, a subset of EBV-infected humanized NOG mice were found to develop LPD containing Hodgkin-like cells with marked nucleoli and Reed-Sternberglike cells with multiple nuclei, suggesting that modeling of EBV-positive Hodgkin lymphoma might be possible in humanized mice. ${ }^{23}$ Notably, one of the earliest versions of newgeneration humanized mice prepared from NOD/scid mice displayed latency II type of EBV gene expression $\left(\mathrm{EBNA1}^{+}\right.$, $\left.\mathrm{LMP}^{+}, \mathrm{LMP}^{+}, \mathrm{EBNA}^{-}, \mathrm{Qp}^{+}\right)$, which is characteristic of EBV-positive Hodgkin lymphoma. ${ }^{28}$

EBV mutants with specific genes knocked out by homologous recombination have been examined in humanized mice, yielding interesting results. EBNA3B is one of the six EBNAs expressed in lymphoblastoid cells transformed by the virus, but EBNA3B-knockout EBV transforms B cells in vitro as efficiently as does the wild-type virus. Characterization of EBNA3B mutants in humanized NSG mice gave the unexpected finding 


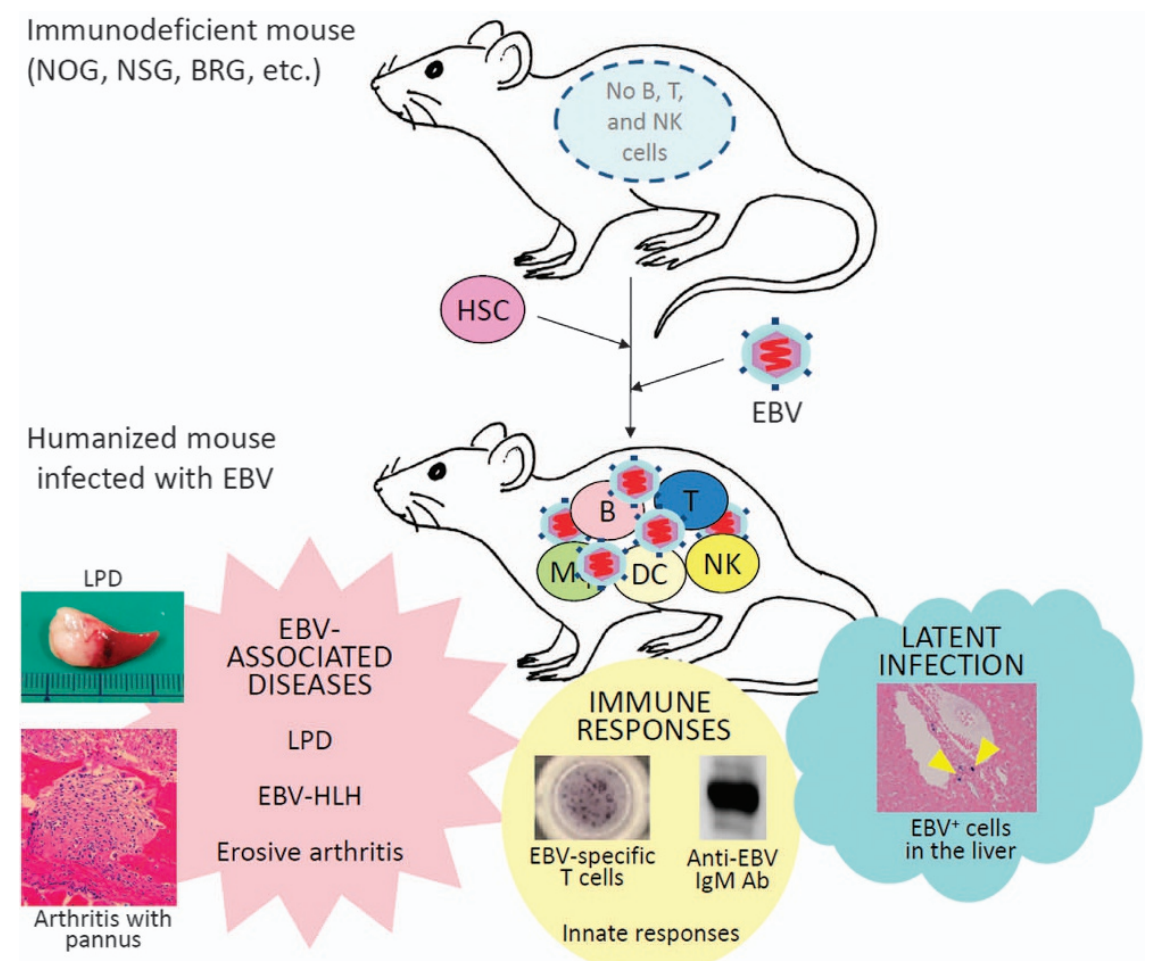

Figure 1 Humanized mouse models of Epstein-Barr virus (EBV) infection. Highly immunodeficient mice of various strains, such as

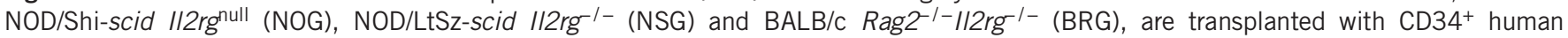
hematopoietic stem cells (HSCs). Consequently, functional human immune system components, including B cells, T cells, natural killer (NK) cells, macrophages and dendritic cells, are reconstituted. These humanized mice can be infected with EBV and reproduce cardinal features of EBV-associated diseases, such as B-cell lymphoproliferative disease (LPD), EBV-associated hemophagocytic lymphohistiocytosis (EBV-HLH) and rheumatoid arthritis (RA). Low-dose infection leads to asymptomatic persistent EBV infection. Both innate and adaptive immune responses to EBV are elicited in humanized mice.

that the mutant virus has an enhanced ability to induce LPD. EBNA3B was also shown to upregulate the expression of the T-cell chemoattractant CXCL10 and thereby facilitate T-cell control of EBV-induced lymphoproliferation. ${ }^{27}$ These results indicate that EBNA3B is a virus-encoded tumor suppressor gene. In similar studies examining EBV mutants in BLT-NSG mice, the role of BZLF1, an immediate-early EBV gene that works as a trigger of viral reactivation from latency, in lymphomagenesis was investigated. ${ }^{25,26}$ The results clearly showed that BZLF1, through the induction of abortive lytic infection, enhances lymphomagenesis in vivo, although the exact mechanism was not revealed. EBV encodes a cluster of three microRNAs (miRNAs) in the BHRF1 locus. In vitro studies have indicated that these three miRNAs cooperate and thereby have an important role in the transformation of B cells by EBV. ${ }^{29,30}$ However, an in vivo study with humanized NSG mice revealed that a mutant EBV lacking all three BHRF1 miRNAs induced lymphomas as efficiently as the wild-type virus, although the mutant had slower kinetics at establishing systemic infection. ${ }^{31}$ In this experiment, only a fraction $(30 \%)$ of the tumors induced by the control wild-type EBV expressed BHRF1 miRNAs, and this may be the reason why no significant difference in tumorigenesis was observed between the wild-type virus and the mutant virus.

\section{EBV-associated HLH}

HLH is a hyperinflammatory condition caused by highly activated but ineffective immune responses. ${ }^{32}$ The clinical features of HLH, mostly caused by the overproduction of inflammatory cytokines by highly activated $\mathrm{T}$ cells and macrophages, include pancytopenia, coagulation defects and the characteristic pathological finding of hemophagocytosis (phagocytosis of autologous blood cells by highly activated macrophages). EBV-associated HLH (EBV-HLH), occurring most often following primary EBV infection, is characterized by monoclonal or oligoclonal proliferation of EBV-infected $\mathrm{T}$ cells or less often NK cells, ${ }^{33,34}$ although a recent paper reported that EBV-associated B-cell proliferation can also be associated with HLH in patients with X-linked LPDs 1 and 2.35 Sato et al. ${ }^{36}$ have described persistent viremia, leukocytosis, interferon- $\gamma$ cytokinemia, normocytic anemia and thrombocytopenia in humanized NOG mice acutely infected with EBV. These mice were found to exhibit systemic $\mathrm{CD}^{+}$T-cell infiltration and prominent hemophagocytosis in the bone marrow. From these findings, the authors proposed that EBV-infected humanized mice may be a useful model for EBV-HLH, although EBV infection of T or NK cells was not observed in these mice. ${ }^{36}$ In contrast to the above findings by Sato et al., ${ }^{36}$ Yajima et al., ${ }^{23}$ as already mentioned, mainly observed B-cell LPD in the same EBV-infected humanized 
NOG mouse model, and the reason for this discrepancy is not clear. However, there are a number of differences in the protocol of mouse humanization between the two studies, including the age of mice at transplantation of HSCs, the route of transplantation and the sex of the mice. ${ }^{36}$ These differences may have resulted in a wide diversity in the strength of T-cell responses to EBV.

\section{Erosive arthritis resembling RA}

Evidence has accumulated implicating EBV in the pathogenesis of RA, an autoimmune disease characterized by polyarthritis with synovial proliferation and destruction of the bone and cartilage tissues. ${ }^{37,38}$ The evidence associating EBV with RA includes a high anti-EBV antibody titer, a high peripheral blood EBV DNA load and a large number of activated EBVspecific $\mathrm{T}$ cells in patients with RA. ${ }^{38}$ In addition, EBV-infected synovial cells that express latent- and lytic-cycle viral genes have been found in RA lesions. ${ }^{39,40}$ However, these pieces of evidence are indirect, and a direct indication for the etiologic role of EBV in RA has been lacking. Recent experiments with humanized mice provided the first direct evidence that EBV can cause erosive arthritis similar to RA in an animal model. ${ }^{41}$ Fifteen of twenty-three humanized NOG mice infected with EBV were found to develop arthritis with massive synovial proliferation and destruction of bone tissue. Notably, the pannus, a histological structure pathognomonic in RA, was recognized in this arthritis. Osteoclasts found in this pannus structure were shown to be of human origin (Nagasawa et al., unpublished results). Bone marrow edema, another histological finding characteristic of RA, was also demonstrated in these mice. Human T cells of both $\mathrm{CD}^{+}$and $\mathrm{CD} 8^{+}$lineages, B cells and macrophages were found infiltrating the arthritis lesions. Few EBV-infected cells were found in the synovia of affected joints, but a number of infected cells were found in the bone marrow adjacent to the affected joints. Although these results clearly show that EBV can induce erosive arthritis resembling $\mathrm{RA}$ in humanized mice, the evidence obtained so far is restricted to morphological findings, and further studies addressing the molecular pathogenesis are required. Because EBV has also been implicated in other autoimmune diseases, such as multiple sclerosis, systemic lupus erythematosus and Sjögren syndrome, ${ }^{42}$ a thorough examination of EBV-infected humanized mice might reveal signs of these diseases.

\section{ASYMPTOMATIC, PERSISTENT EBV INFECTION IN HUMANIZED MICE}

The vast majority of EBV infections in humans result in viral latency maintained by $\mathrm{T}$-cell immunosurveillance by the host; any conditions that compromise the host's T-cell immune function can disrupt the latency and reactivate the infection. Following the infection of humanized NOG mice with lower doses ( $<10^{1} 50 \%$ transforming dose) of EBV, viral DNA was detected only transiently in the peripheral blood, and the mice survived without any apparent signs of disease. ${ }^{23}$ However, EBV was not eradicated from these mice because small numbers of EBV-encoded small RNA-positive B cells were consistently found in their spleens and livers up to 220 days after infection. This apparently asymptomatic persistent infection may be a recapitulation of EBV latency in humans, although further characterization is necessary to confirm that this condition is maintained by the host's immunosurveillance.

In EBV infection of humans, the pattern of viral gene expression differs depending on the differentiation status of the host $B$ cells. On infection of naive $B$ cells, EBV expresses six EBNAs (EBNAs 1, 2, 3A, 3B, 3C and LP) using the $\mathrm{Cp}$ promoter, three LMPs (LMPs 1, 2A and 2B), EBV-encoded small RNAs and miRNAs (latency III). In contrast, EBVinfected germinal center B cells express only EBNA1, LMPs, EBV-encoded small RNA $s$ and miRNAs (latency II); here, the Qp promoter (instead of $\mathrm{Cp}$ ) is used to transcribe the EBNA1 gene. Latency I, observed in EBV-infected memory B cells in their homeostatic proliferative phase, is characterized by the expression of EBNA1 as the only viral protein, with its mRNA transcribed from Qp. The mechanism of this differential regulation of EBV gene expression is not known. Recent experiments with EBV-infected humanized NSG mice showed that the number of EBV-infected B cells in latencies I and II decreased significantly when $\mathrm{CD} 4^{+} \mathrm{T}$ cells were depleted. ${ }^{43}$ This finding suggests that $\mathrm{CD}^{+} \mathrm{T}$ cells are involved in the regulation of latent $\mathrm{EBV}$ gene expression in $\mathrm{B}$ cells, leading to the generation of the latency I or latency II phenotype.

\section{IMMUNE RESPONSES TO EBV IN HUMANIZED MICE}

\section{Adaptive immune responses}

A great advantage of new-generation humanized mice is their ability to mount human immune responses to infectious agents. In BLT mice, the presence of the human thymic organoid enables the education of T cells in the human thymic environment and allows the development of a highly diverse T-cell repertoire restricted by human MHC. ${ }^{22,44}$ Furthermore, this recapitulation of human $\mathrm{T}$-cell development facilitates T-cell interaction with $\mathrm{B}$ cells and thereby efficient antibody production with class-switch recombination. ${ }^{45,46}$ As described above, Melkus et al. ${ }^{22}$ have described efficient EBV-specific $\mathrm{T}$-cell responses restricted by human MHC in BLT-NOD mice. EBV-specific antibody responses in BLT mice have not been described.

EBV-specific T-cell responses restricted by human $\mathrm{MHC}$ have been induced not only in BLT mice but also in other types of humanized mice. $\mathrm{CD}^{+} \mathrm{T}$ cells isolated from EBV-infected

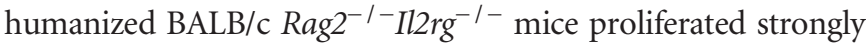
following stimulation with autologous EBV-transformed B cells, suggesting that EBV-specific T-cell responses were induced. ${ }^{17}$ EBV-specific T-cell responses restricted by human MHC class I have been clearly demonstrated in humanized NOG mice. ${ }^{23}$ Importantly, the $\mathrm{CD}^{+} \mathrm{T}$-cell responses in these mice were shown to have a protective role. ${ }^{47}$ Depletion of $\mathrm{CD}^{+}{ }^{+} \mathrm{T}$ cells or $\mathrm{CD}^{+} \mathrm{T}$ cells by intravenous injection of antiCD3 or anti-CD8 antibodies, respectively, enhanced EBVinduced lymphoproliferation and significantly reduced the lifespan of the mice. ${ }^{47}$ Furthermore, $\mathrm{CD}^{+} \mathrm{T}$ cells isolated from EBV-infected humanized NOG mice suppressed the 
in vitro transformation of autologous $\mathrm{B}$ cells by EBV. ${ }^{47}$ EBV-specific and human MHC-restricted T-cell responses with protective value have also been described in humanized NSG mice. ${ }^{24} \mathrm{EBV}$-specific $\mathrm{T}$ cells isolated from these mice exhibited cytolytic activity against autologous EBV-infected B cells, although they tended to recognize subdominant epitopes that are not frequently recognized in human EBV infection. Notably, $\mathrm{T}$ cells specific to lytic-cycle EBV proteins are dominant over those specific to latent-cycle proteins during acute infection of humanized NSG mice. This finding seems to reflect the predominant $\mathrm{T}$-cell responses to lytic-cycle EBV proteins described in acute human EBV infection. ${ }^{48}$

In humanized mice other than BLT mice, human $\mathrm{T}$ cells are positively selected in the murine thymus, probably through the interaction of their T-cell receptors with murine MHC proteins expressed by thymic epithelial cells. ${ }^{49}$ This aberrant selection of $\mathrm{T}$ cells is probably one of the main causes of the suboptimal development of $\mathrm{T}$ cells in these mice. This problem of T-cell education has been alleviated by introducing a human $\mathrm{MHC}$ transgene into humanized mice. Shultz and co-workers ${ }^{24,50}$ have prepared humanized NSG mice with a human transgene encoding HLA-A2, and these mice demonstrated efficient EBVspecific T-cell responses restricted by this particular $\mathrm{MHC}$ molecule.

The induction of humoral immune responses to EBV in humanized mice appears to be much less effective than the induction of cell-mediated immune responses. A report by Yajima et al. $^{23}$ demonstrating IgM antibodies specific for a major component of the EBV capsid, p18 $8^{\mathrm{BZLF} 3}$, is to our knowledge the only publication describing the antibody response to EBV in humanized mice.

\section{Innate immune responses}

Innate immunity has an essential role in the control of viral infections, and aberrant susceptibility to herpesvirus infection, including $\mathrm{EBV}$, has been reported in patients with selective deficiency of NK cells. ${ }^{51}$ Although innate immune responses to EBV have not been extensively studied in humans, Chijioke et al..$^{52}$ used humanized mice to reveal the interesting roles of innate immune cells in controlling primary EBV infection. The depletion of NK cells from EBV-infected humanized NSG mice resulted in a higher EBV DNA load in the spleen, exaggerated $\mathrm{CD}^{+} \mathrm{T}$-cell responses to the virus and an increased risk of EBV-induced lymphoproliferation. ${ }^{52}$ These results clearly show an important role for $\mathrm{NK}$ cells in controlling primary EBV infection and suggest that decreased NK cell activity is associated with a high risk of developing infectious mononucleosis.

\section{Studies on immunotherapies and vaccines}

Because effective anti-EBV immune responses have been described in humanized mice, efforts have been made to use these mice as a platform to study immunotherapies and vaccines to control EBV infection. Vaccination of humanized NSG mice with a fusion protein of EBNA1 and a monoclonal antibody specific to the human endocytic receptor DEC-205, in combination with the Toll-like receptor 3 ligand polyI:C as an adjuvant, was found to prime EBNA1-specific $\mathrm{T}$ cells and induce IgM antibodies specific for EBNA1. ${ }^{53}$ EBNA1-specific $\mathrm{CD}^{+}{ }^{+} \mathrm{T}$-cell clones with the ability to recognize autologous EBV-transformed lymphoblastoid cells have been isolated from these mice. ${ }^{54}$

\section{MOUSE XENOGRAFT MODELS OF EBV-ASSOCIATED T-/NK CELL LPD}

As described in another article in this issue, EBV infects not only $\mathrm{B}$ cells but also $\mathrm{T}$ and $\mathrm{NK}$ cells, and on rare occasions causes EBV-associated T-/NK cell LPD. Although EBV infection of $\mathrm{B}$ cells is readily reproduced in humanized mice, no evidence thus far has been obtained for infection of $\mathrm{T}$ or NK cells. Therefore, to reproduce the features of chronic active EBV infection (CAEBV), a representative disease of EBVassociated T-/NK cell LPD, NOG mice were transplanted intravenously with PBMCs obtained from patients with the disease. ${ }^{55}$ This xenotransplantation resulted in the engraftment and systemic proliferation of EBV-infected $\mathrm{T}$ or $\mathrm{NK}$ cells, depending on which cell type was infected in the patient. T-cell receptor repertoire analyses clearly indicated that an identical clone of EBV-infected $\mathrm{T}$ cells was proliferating in the patients and the mice that received the PBMCs. High levels of human cytokines/chemokines, including interferon- $\gamma$, interleukin- 8 and RANTES (regulated on activation normal T cell expressed and secreted), were detected in the sera of these mice, reproducing hypercytokinemia characteristic of CAEBV. CAEBV can be divided into four types, namely the CD4, CD8, $\gamma \delta \mathrm{T}$ and NK types, depending on which cell lineage is infected in the patient, and transplantation of the patients' PBMCs resulted in the engraftment of EBV-infected T or NK cells in all four types of CAEBV. Notably, isolated fractions containing EBV-infected cells, for example, a $\mathrm{CD}^{+}$cell fraction isolated from CD8-type patients, did not result in the engraftment of EBV-infected cells. The only exception was the $\mathrm{CD}^{+}$fraction obtained from CD4-type patients. When the $\mathrm{CD}^{+}{ }^{+}$fraction was removed from PBMCs, engraftment was prevented in patients with each of the four types of CAEBV. Finally, if the isolated EBV-infected cell fraction that did not engraft on its own was transplanted together with autologous $\mathrm{CD}^{+}$cells, engraftment of the EBV-infected cells was observed. These results strongly suggest that the engraftment of EBV-infected T and NK cells requires the presence of $\mathrm{CD} 4{ }^{+}$ cells, regardless of whether the particular fraction is infected. This notion was confirmed by the result that administration of the OKT-4 antibody to deplete $\mathrm{CD}^{+}$cells following the transplantation of PBMCs prevented the engraftment of EBV-infected NK cells. ${ }^{55}$ It is thus expected that a novel therapy targeting $\mathrm{CD}^{+} \mathrm{T}$ cells or their products may be possible.

As described in a previous section, EBV-HLH is characterized by the proliferation of EBV-infected T (or sometimes NK) cells and is therefore included in the category of EBVassociated T-/NK cell LPD. Similar to the above findings on CAEBV, xenotransplantation of PBMCs from patients with 
EBV-HLH also resulted in the engraftment of EBV-infected $\mathrm{T}$ cells. ${ }^{55}$ However, there were clear differences between the CAEBV mouse model and EBV-HLH mouse model. Hypercytokinemia was more pronounced in EBV-HLH mice than in CAEBV mice. EBV-HLH mice died earlier than CAEBV mice and showed hemorrhagic lesions in the thoracic and/or abdominal cavities, probably reflecting the hemorrhagic tendency in HLH. Another unexpected finding in EBV-HLH mice was that their spleens and livers contained EBV-infected B cells, but not $\mathrm{T}$ cells, although the peripheral blood contained only the virus-infected $\mathrm{T}$ cells. At present, this discrepancy cannot be explained.

Recently, Murata et al..$^{56}$ set up a new xenograft model for EBV-associated T-/NK cell LPD by subcutaneously transplanting NOG mice with cells from the EBV-positive NK cell line SNK6, established from a patient with nasal-type extranodal NK/T-cell lymphoma. This model was used to show the effect of heat-shock protein 90 inhibitors and histone deacetylase inhibitors on suppressing the growth of EBV-positive NK cells in vivo. 56,57

\section{PERSPECTIVE}

Humanized mice are rapidly being improved. For example, the transfer of human cytokines to humanized mice, either by direct injection of proteins, introduction of transgenes or knock-in recombination, will continue to improve the development and function of the human immune system components in humanized mice. ${ }^{58}$ Humanized mice improved in this manner will recapitulate human EBV infection more accurately than the current models. One of the primary targets of EBV is epithelial cells, and the complete lifecycle of EBV requires both $\mathrm{B}$ cells and epithelial cells. The introduction of human epithelial components to humanized mice is therefore likely to expand the EBV pathogenesis that is reproducible in them. Inoculation of mice with $\mathrm{EBV}$ via the oral route, which is the normal pathway of EBV propagation, might be possible in humanized mice with human epithelial tissue grafts.

Thus far, EBV-associated B-cell LPD is the only malignant disease reproduced in humanized mice. Other EBV-associated malignancies, such as Burkitt lymphoma, Hodgkin lymphoma and nasopharyngeal carcinoma, have not been recapitulated. These malignancies appear to be multifactorial and require the involvement of cofactors such as malaria infection, human immunodeficiency virus type 1 infection and carcinogens. Experiments to examine the interplay between EBV and these cofactors could be carried out in humanized mice.

Humanized mice may also be used to recapitulate genetically predisposed aberrant immune responses to EBV. The transplantation of HSCs that have been directly isolated from patients with primary immunodeficiencies, or indirectly produced (by induced pluripotent stem cells established from patient cells), may generate humanized mice that mirror the immunological defects of patients. In addition, genetic manipulation of HSCs to shut down or upregulate the expression of specific genes may also make it possible to analyze the roles of particular human genes in controlling EBV infection in vivo.

\section{CONFLICT OF INTEREST}

The authors declare no conflict of interest.

\section{ACKNOWLEDGEMENTS}

Studies in our laboratory were supported by grants from the Ministry of Health, Labor and Welfare of Japan (H24-Nanchi-046 and H26-Nanchi-013), a Grant from the National Center for Child Health and Development (25-9) and the Grant-in-Aid for Scientific Research (25670198).

1 Shope T, Dechairo D, Miller G. Malignant lymphoma in cottontop marmosets after inoculation with Epstein-Barr virus. Proc Natl Acad Sci USA 1973; 70: 2487-2491.

2 Epstein MA, Morgan AJ, Finerty S, Randle BJ, Kirkwood JK. Protection of cottontop tamarins against Epstein-Barr virus-induced malignant lymphoma by a prototype subunit vaccine. Nature 1985; 318: 287-289.

3 Epstein MA, zur Hausen H, Ball G, Rabin H. Pilot experiments with EB virus in owl monkeys (Aotus trivirgatus). III. Serological and biochemical findings in an animal with reticuloproliferative disease. Int J Cancer 1975; 15: 17-22.

4 Johannessen I, Crawford DH. In vivo models for Epstein-Barr virus (EBV)associated B cell lymphoproliferative disease (BLPD). Rev Med Virol 1999, 9: 263-277.

5 Takashima K, Ohashi M, Kitamura Y, Ando K, Nagashima K, Sugihara H et al. A new animal model for primary and persistent Epstein-Barr virus infection: human EBV-infected rabbit characteristics determined using sequential imaging and pathological analysis. J Med Virol 2008; 80: 455-466.

6 Rajcani J, Szenthe K, Durmanova V, Toth A, Asvanyi B, Pitlik E et al. Epstein-Barr virus (HHV-4) inoculation to rabbits by intranasal and oral routes results in subacute and/or persistent infection dissimilar to human disease. Intervirology 2014; 57: 254-269.

7 Okuno K, Takashima K, Kanai K, Ohashi M, Hyuga R, Sugihara H et al. Epstein-Barr virus can infect rabbits by the intranasal or peroral route: an animal model for natural primary EBV infection in humans. J Med Virol 2010; 82: 977-986.

8 Moghaddam A, Rosenzweig M, Lee-Parritz D, Annis B, Johnson RP, Wang F. An animal model for acute and persistent Epstein-Barr virus infection. Science 1997; 276: 2030-2033.

9 Wang F. Nonhuman primate models for Epstein-Barr virus infection. Curr Opin Virol 2013; 3: 233-237.

10 Sashihara J, Hoshino Y, Bowman JJ, Krogmann T, Burbelo PD, Coffield VM et al. Soluble rhesus lymphocryptovirus gp350 protects against infection and reduces viral loads in animals that become infected with virus after challenge. PLoS Pathogen 2011; 7: e1002308.

11 Blaskovic D, Stancekova M, Svobodova J, Mistrikova J. Isolation of five strains of herpesviruses from two species of free living small rodents. Acta Virol 1980; 24: 468

12 Barton E, Mandal P, Speck SH. Pathogenesis and host control of gammaherpesviruses: lessons from the mouse. Annu Rev Immunol 2011 29: 351-397.

13 Mosier DE, Gulizia RJ, Baird SM, Wilson DB. Transfer of a functional human immune system to mice with severe combined immunodeficiency. Nature 1988; 335: 256-259.

14 Bosma GC, Custer RP, Bosma MJ. A severe combined immunodeficiency mutation in the mouse. Nature 1983; 301: 527-530.

15 Fujiwara S, Matsuda G, Imadome K. Humanized mouse models of Epstein-Barr virus infection and associated diseases. Pathogens 2013; 2 $153-176$.

16 Ito M, Hiramatsu H, Kobayashi K, Suzue K, Kawahata M, Hioki K et al. NOD/SCID/gamma(c)(null) mouse: an excellent recipient mouse model for engraftment of human cells. Blood 2002; 100: 3175-3182.

17 Traggiai E, Chicha L, Mazzucchelli L, Bronz L, Piffaretti JC, Lanzavecchia A et al. Development of a human adaptive immune system in cord blood cell-transplanted mice. Science 2004; 304: 104-107.

18 Ishikawa F, Yasukawa M, Lyons B, Yoshida S, Miyamoto T, Yoshimoto G et al. Development of functional human blood and immune systems in NOD/SCID/IL2 receptor \{gamma\} chain(null) mice. Blood 2005; 106: 1565-1573. 
19 Shultz LD, Brehm MA, Garcia-Martinez JV, Greiner DL. Humanized mice for immune system investigation: progress, promise and challenges. Nat Rev Immunol 2012; 12: 786-798.

20 Akkina R. New generation humanized mice for virus research: comparative aspects and future prospects. Virology 2013; 435: 14-28.

21 Leung C, Chijioke O, Gujer C, Chatterjee B, Antsiferova O, Landtwing V et al. Infectious diseases in humanized mice. Eur J Immunol 2013; 43: 2246-2254.

22 Melkus MW, Estes JD, Padgett-Thomas A, Gatlin J, Denton PW, Othieno FA et al. Humanized mice mount specific adaptive and innate immune responses to EBV and TSST-1. Nat Med 2006; 12: 1316-1322.

23 Yajima M, Imadome K, Nakagawa A, Watanabe S, Terashima K, Nakamura $\mathrm{H}$ et al. A new humanized mouse model of Epstein-Barr virus infection that reproduces persistent infection, lymphoproliferative disorder, and cell-mediated and humoral immune responses. J Infect Dis 2008; 198: 673-682.

24 Strowig T, Gurer C, Ploss A, Liu YF, Arrey F, Sashihara J et al. Priming of protective $T$ cell responses against virus-induced tumors in mice with human immune system components. J Exp Med 2009; 206: 1423-1434.

25 Ma SD, Hegde S, Young KH, Sullivan R, Rajesh D, Zhou Y et al. A new model of Epstein-Barr virus infection reveals an important role for early lytic viral protein expression in the development of lymphomas. J Virol 2011; 85: 165-177.

$26 \mathrm{Ma}$ SD, Yu X, Mertz JE, Gumperz JE, Reinheim E, Zhou Y et al. An Epstein-Barr virus (EBV) mutant with enhanced BZLF1 expression causes lymphomas with abortive lytic EBV infection in a humanized mouse model. J Virol 2012; 86: 7976-7987.

27 White RE, Ramer PC, Naresh KN, Meixlsperger S, Pinaud L, Rooney C et al. EBNA3B-deficient EBV promotes $B$ cell lymphomagenesis in humanized mice and is found in human tumors. J Clin Invest 2012; 122: 1487-1502.

28 Islas-Ohlmayer M, Padgett-Thomas A, Domiati-Saad R, Melkus MW, Cravens PD, Martin Mdel $P$ et al. Experimental infection of NOD/SCID mice reconstituted with human CD34+ cells with Epstein-Barr virus. J Virol 2004; 78: 13891-13900.

29 Seto E, Moosmann A, Gromminger S, Walz N, Grundhoff A, Hammerschmidt W. Micro RNAs of Epstein-Barr virus promote cell cycle progression and prevent apoptosis of primary human B cells. PLOS Pathogen 2010; 6: e1001063.

30 Feederle R, Linnstaedt SD, Bannert H, Lips H, Bencun M, Cullen BR et al. A viral microRNA cluster strongly potentiates the transforming properties of a human herpesvirus. PLoS Pathogen 2011; 7: e1001294.

31 Wahl A, Linnstaedt SD, Esoda C, Krisko JF, Martinez-Torres F, Delecluse $\mathrm{HJ}$ et al. A cluster of virus-encoded microRNAs accelerates acute systemic Epstein-Barr virus infection but does not significantly enhance virus-induced oncogenesis in vivo. J Virol 2013; 87: 5437-5446.

32 Henter JI, Horne A, Arico M, Egeler RM, Filipovich AH, Imashuku S et al. HLH-2004: diagnostic and therapeutic guidelines for hemophagocytic lymphohistiocytosis. Pediatr Blood Cancer 2007; 48: 124-131.

33 Kikuta H, Sakiyama Y, Matsumoto S, Oh-Ishi T, Nakano T, Nagashima T et al. Fatal Epstein-Barr virus-associated hemophagocytic syndrome. Blood 1993; 82: 3259-3264.

34 Kawaguchi H, Miyashita T, Herbst H, Niedobitek G, Asada M, Tsuchida M et al. Epstein-Barr virus-infected $\mathrm{T}$ lymphocytes in Epstein-Barr virusassociated hemophagocytic syndrome. J Clin Invest 1993; 92: 1444-1450.

35 Yang X, Wada T, Imadome K, Nishida N, Mukai T, Fujiwara $\mathrm{M}$ et al. Characterization of Epstein-Barr virus (EBV)-infected cells in EBVassociated hemophagocytic lymphohistiocytosis in two patients with X-linked lymphoproliferative syndrome type 1 and type 2. Herpesviridae 2012; 3: 1 .

36 Sato K, Misawa N, Nie C, Satou Y, Iwakiri D, Matsuoka M et al. A novel animal model of Epstein-Barr virus-associated hemophagocytic lymphohistiocytosis in humanized mice. Blood 2011; 117: 5663-5673.

37 McInnes IB, Schett G. The pathogenesis of rheumatoid arthritis. N Engl J Med 2011; 365: 2205-2219.

38 Toussirot E, Roudier J. Pathophysiological links between rheumatoid arthritis and the Epstein-Barr virus: an update. Joint Bone Spine 2007; 74: 418-426.

39 Takei M, Mitamura K, Fujiwara S, Horie T, Ryu J, Osaka S et al. Detection of Epstein-Barr virus-encoded small RNA 1 and latent membrane protein 1 in synovial lining cells from rheumatoid arthritis patients. Int Immunol 1997; 9: 739-743.

40 Takeda T, Mizugaki Y, Matsubara L, Imai S, Koike T, Takada K. Lytic Epstein-Barr virus infection in the synovial tissue of patients with rheumatoid arthritis. Arthritis Rheum 2000; 43: 1218-1225.
41 Kuwana Y, Takei M, Yajima M, Imadome K, Inomata H, Shiozaki M et al. Epstein-Barr virus induces erosive arthritis in humanized mice. PLoS One 2011; 6: e26630.

42 Niller HH, Wolf H, Ay E, Minarovits J. Epigenetic dysregulation of EpsteinBarr virus latency and development of autoimmune disease. Adv Exp Med Biol 2011; 711: 82-102.

43 Heuts F, Rottenberg ME, Salamon D, Rasul E, Adori M, Klein G et al. $T$ cells modulate Epstein-Barr virus latency phenotypes during infection of humanized mice. J Virol 2014; 88: 3235-3245.

44 Lan P, Tonomura N, Shimizu A, Wang S, Yang YG. Reconstitution of a functional human immune system in immunodeficient mice through combined human fetal thymus/liver and CD34+ cell transplantation. Blood 2006; 108: 487-492.

45 Sun Z, Denton PW, Estes JD, Othieno FA, Wei BL, Wege AK et al. Intrarectal transmission, systemic infection, and $\mathrm{CD} 4+\mathrm{T}$ cell depletion in humanized mice infected with HIV-1. J Exp Med 2007; 204: 705-714.

46 Brainard DM, Seung E, Frahm N, Cariappa A, Bailey CC, Hart WK et al. Induction of robust cellular and humoral virus-specific adaptive immune responses in human immunodeficiency virus-infected humanized BLT mice. J Virol 2009; 83: 7305-7321.

47 Yajima M, Imadome K, Nakagawa A, Watanabe S, Terashima K, Nakamura $\mathrm{H}$ et al. T cell-mediated control of Epstein-Barr virus infection in humanized mice. J Infect Dis 2009; 200: 1611-1615.

48 Hislop AD, Taylor GS, Sauce D, Rickinson AB. Cellular responses to viral infection in humans: lessons from Epstein-Barr virus. Annu Rev Immunol 2007; 25: 587-617.

49 Watanabe Y, Takahashi T, Okajima A, Shiokawa M, Ishii N, Katano I et al. The analysis of the functions of human $B$ and $T$ cells in humanized NOD/shi-scid/gammac(null) (NOG) mice (hu-HSC NOG mice). Int Immunol 2009; 21: 843-858.

50 Shultz LD, Saito $Y$, Najima $Y$, Tanaka S, Ochi T, Tomizawa $M$ et al. Generation of functional human T-cell subsets with HLA-restricted immune responses in HLA class I expressing NOD/SCID/IL2r gamma(null) humanized mice. Proc Natl Acad Sci USA 2010; 107: 13022-13027.

51 Orange JS. Natural killer cell deficiency. J Allergy Clin Immunol 2013; 132: $515-525$ quiz 526.

52 Chijioke O, Muller A, Feederle R, Barros MH, Krieg C, Emmel V et al. Human natural killer cells prevent infectious mononucleosis features by targeting lytic Epstein-Barr virus infection. Cell Rep 2013; 5: 1489-1498.

53 Leung CS, Maurer MA, Meixlsperger S, Lippmann A, Cheong C, Zuo J et al. Robust T-cell stimulation by Epstein-Barr virus-transformed $B$ cells after antigen targeting to DEC-205. Blood 2013; 121: 1584-1594.

54 Meixlsperger S, Leung CS, Ramer PC, Pack M, Vanoaica LD, Breton G et al. CD141+ dendritic cells produce prominent amounts of IFN-alpha after dsRNA recognition and can be targeted via DEC-205 in humanized mice. Blood 2013; 121: 5034-5044.

55 Imadome K, Yajima M, Arai A, Nakazawa A, Kawano F, Ichikawa S et al. Novel mouse xenograft models reveal a critical role of CD4+ T cells in the proliferation of EBV-infected T and NK cells. PLoS Pathogen 2011; 7: e1002326.

56 Murata T, Iwata S, Siddiquey MN, Kanazawa T, Goshima F, Kawashima D et al. Heat shock protein 90 inhibitors repress latent membrane protein 1 (LMP1) expression and proliferation of Epstein-Barr virus-positive natural killer cell lymphoma. PLoS One 2013; 8: e63566.

57 Siddiquey MN, Nakagawa H, Iwata S, Kanazawa T, Suzuki M, Imadome K et al. Anti-tumor effects of suberoylanilide hydroxamic acid on Epstein-Barr virus-associated T cell and natural killer cell lymphoma. Cancer Sci 2014; 105: 713-722.

58 Rongvaux A, Takizawa H, Strowig T, Willinger T, Eynon EE, Flavell RA et al. Human hemato-lymphoid system mice: current use and future potential for medicine. Annu Rev Immunol 2013; 31: 635-674.

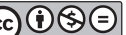

This work is licensed under a Creative Commons Attribution-NonCommercial-NoDerivs 3.0 Unported License. The images or other third party material in this article are included in the article's Creative Commons license, unless indicated otherwise in the credit line; if the material is not included under the Creative Commons license, users will need to obtain permission from the license holder to reproduce the material. To view a copy of this license, visit http://creativecommons.org/licenses/by-nc-nd/3.0/ 